\title{
Consideraciones sobre la proyección del Derecho indiano en la legislación civil peruana del Siglo XIX Jorge Basadre Ayulo
}

En el año de 1825 culminó el corto proceso de autodeterminación republicana de América que conllevó la pérdida de dominio de la corona espanola sobre trece territorios: Argentina, Chile, Perú, Ecuador, Bolivia, Venezuela. Colombia, México, América Central, Paraguay, Uruguay, Santo Domingo y la zona de la Florida en el norte del continente. Los virreinatos de Nueva España, Perú, Nueva Granada y Río de la Plata sirvieron de base a las nuevas repúblicas creadas por la libre determinación popular, por los títulos indianos bajo el gobierno de los borbones y el reconocimiento de un estado posesorio preexistente con el hito cronológico de 1810 (1). La división política indiana, de acuerdo a la mutilación borbó. nica, sirvió de patrón creativo a las repúblicas independientes que nacieron de este proceso. También, fenecieron las capitanías generales de Chile, Charcas, Quito, Venezuela, Santo Domingo, Guatemala, Yucatán y Nueva Galicia para integrar naciones independientes.

Dieciséis millones de personas hicieron un salto al vacio al adoptar una nueva forma política y esta organización iba a traer como consecuencia inevitable la creación de nuevas estructuras jurídicas y la asimilación del novedoso proceso codificador iniciado en Austria y Prusia y culminado con los textos napoleónicos de Francia. Pese a todo ello, el espíritu del derecho indiano no desapareció totalmente y la influencia de España continuó vigente en este proceso codificador republicano americano iniciado en el siglo XIX.

(1) Basadre, Jorge. Mistoria de la Repablica del Penu.. Tomo I, página 203. Lima, 1962.

En esta cita se utiliza el texto de la penúltima edición de Historia de la Republica del Porú. 
A fin de examinar el caso particular y especifico de la república del Perú, ésta se había declarado libre e independiente el 28 de julio de 1821 , con actos rituales realizados en cuatro lugares céntricos de Lima: la plaza mayor y las plazuelas de Santa Ana y de la Inquisición. No obstante esta declaración de libertad, las bases de la república peruana no llegaron a establecer con plenitud hasta el año de 1842, cuando ya el Estado adquiere forma juridica y se solucionan los problemas limítrofes derivados en sus relaciones con las nuevas repúblicas vecinas de Colombia, Chile y Bolivia (2).

Al iniciarse esta etapa independentista, mucha de la antigua legislación indiana siguió rigiendo mediante un lento proceso de "recepción selectiva" y conservada en la etapa de derecho intermedio que es anterior al proceso codificador civil y procesal civil, que empezó en 1852, aunque la república había ido a la promulgación de los códigos bolivianos durante la etapa fugaz de la Confederación Peruano-Boliviana establecida por Andrés de Santa Cruz. Nuestro estudio sucinto sobre los alcances del derecho indiano en la legislación peruana de los siglos XIX y XX tiene como fin establecer la premisa de que estos principios no desaparecieron totalmente pese a la rotura del vínculo político con la metrópoli española y constituyen material de influencia en el derecho intermedio y en la etapa codificada nacional que se inicia, como quedó expuesto en el año de 1852 con el tex to civil y procesal civil (3).

\section{El derecho intermedio: 1) Iguald ad civil. 2) Esclavitud.}

3) Condición de los indigenas. 4) Estad o e Iglesia. 5) La Propiedad.

\section{Igualdad civil y régimen de las personas}

Estudiando el contenido del derecho intermedio de sus diversos textos (constituciones politicas, leyes, decretos) cabe mencionar distintas tendencias en esta corriente legislativa. Entre ellas, pueden mencionarse la declaración de la independencia nacional con sus hondas y trascendentes repercusiones sobre el estado o condición de las personas desde el punto de vista de la división entre peruanos y extranjeros, $y$, el concepto de la igualdad de los peruanos ante la ley y la abolición de los títulos de nobleza.

(2) Basadre, Jorge. Historia de La Kepública del Peni. Tomo 11, página 166. Lima, 1983, Se utiliza en esta cita el texto de la ultima edición, que fue preparada por el autor desde los
años antes de fallecer en 1980 . 
La distinción entre nobles y plebeyos era originaria de España pero tenia algunas características propias dentro del ambiente americano, Entre sus notas distintivas estaba el pago de impuestos especiales de cargo de nobleza. Sus rentas no eran embargables y no podian ser encarcelados por deudas. Los nobles no podian ser puestos en tormento ni obligados a cantar la "palinodia".

En la América indiana, la nobleza no solamente consistió en los que tenian títulos de Castilla y la formaban también otras personas de rango elevado que habian venido a estas tierras nuevas, sino que hubo una tendencia a crear una nobleza propia compuesta, en primer lugar, por los siguientes conquistadores que tuvieron como fuente patrimonial para crear su nobleza en las concesiones de los monarcas. Se puede distinguir inicialmente entre los nobles trasladados de Espana y la nobleza de los conquistadores. gente originariamente humilde pero que habian obtenido blasones. En el siglo XVIII surgió otro tipo de nobleza: aquellas personas que compraron, adquiriendo mediante el pago de ciertos capitales, la concesión de títulos nobiliarios. Tenemos el caso del virrey Duque de la Palata, cuando se trató de construir las murallas para proteger Lima con el objeto de recabar los fondos necesarios para construir esta obra. El virrey puso en venta títulos de nobleza, que el pueblo con su ingenio llamó "nobleza adobera" o "de barro".

En la época de la conquista se habia producido con España el creciente poder de los monarcas que fueron produciendo restricciones al poder de la nobleza, la que adquiría, a la larga, una característica palaciega pero sin fuerza política. Análogo proceso ocurrió en América. La nobleza fue muy poderosa en los primeros días de la colonia. Los más antiguos conquistadores, obtuvieron grandes territorios en las regiones conquistadas y como, a su vez, el concepto de vecino estaba unido a la noción de propiedad, se produjo en el Perú un fenómeno de identidad entre el municipio representado por la ciudad y una especie de feudo representado por el poder de los conquistadores convertidos en nobles. Pero, a medida que los reyes tuvieron conciencia de la importancia de las tierras descubiertas, comenzaron a suprimir los privilegios que habian otorgado a los conquistadores en las capitulaciones, labor que vinieron a completar los virreyes. Por otra parte, es conocida la forma como se destrozaron los conquistadores entre si mediante las luchas intestinas al comienzo de la colonización, contiendas con las cuales mermaron su poder político en beneficio del poder centralista de la monarquía.

Resulta incompleto estudiar el poder histórico de la nobleza sin mencionar a la nobleza indigena que también desaparece con la república. La 
legislación de indias mantuvo la institución de los caciques, pero la reguló para mantenerla al servicio de los espanioles (4). Ellos fueron los encargados de hacer efectiva la tributación de los indios y constituyeron el órgano intermediario entre las autoridades españolas y los indigenas. Llegaron a tener funciones judiciales limitadas. Estaban exentos del pago de tributos y se les concedió tierras para su cultivo. Tuvieron como forma de sucesión la misma de los mayorazgos, es decir, de padre a hijo. Este abolengo terminó con el inicio de la república.

\section{Esclavitud}

No obstante, la teoría imbíbita en la declaración de la igualdad civil y política, la revolución de la independencia, tanto en América Latina como en Estados Unidos de Norteamérica, conservó el régimen de la es. clavitud de los negros. Lo único que hizo el principio peruano fue declarar libres a los hijos de los esclavos nacidos después del 28 de julio de 1821 y entregarlos bajo el patronato de sus antiguos amos. Bajo el gobierno corto de Salaverry, y durante otros gobiernos republicanos. se autorizo el tráfico de esclavos. Fste se llevaba a cabo entonces primordialmente desde Colombia. La constitución politica de 1839. que regia en el pais en el momento de promulgarse el código civil de 1852, reconoció tácitamente la esclavitud al estatuir que "son peruanos los hombres libres nacidos en el Pení". El fenómeno de la esclavitud existia, pues, aunque mitigado en el momento en que se promulgó este código civil de 1852.

Existieron en América tres clases de tsclavos: los aborigenes o indios. los negros y los blancos.

Los esclavos blancos cran las mujeres de religión mahometana o los descendientes de mahometanos que vinieron a América en el grupo de los expedicionarios como servidumbre de los altos personajes administrativos de la colonia. Como el paso de mujeres a las Indias estaba recortado debido a la condición juridica en que se encontraba la mujer. se presentó el problema de la escasez de mujeres de raza blanca en América que dio

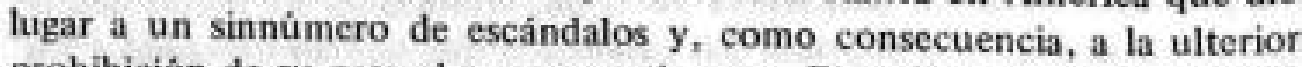
prohibición de su pase al nuevo continente. El tráfico negrero se realizó por concesión a los espanoles, portugueses, franceses, etc. Su traslado se realizaba por tres medios: primero, por licencia real, después por el régimen de asientos o sea las concesiones o monopolios $y$, por último, el libre

(4) Francivo Garcia Cakterón establece que cacioue es el nombre que los pueblos dabas a lus gobernadores de las provincias. Garcja Caklerón. Francisco, Diceionario de Lagílacién
Peruana Lima-Parí, 879 , pagina 317. Tomo I. 
tráfico. Las licencias fueron permisos otorgados por el rey previo pago de derechos y el registro en Sevilla, sea como liberalidad graciosa o al pasar un acaudalado con su servidumbre a las Indias o como instrumento de crédito o de pago. Los asientos fueron negocios jurídicos similares a las licencias, y constituyeron permisos aislados. Por los asientos se entregó la administración de este comercio a una persona determinada para que asumiera el comercio negrero.

El régimen del libre tráfico de esclavos es el beneficio de su comercio sin restricciones y por él se pudieron trasladar negros a América. Este es el tipo de tráfico de negros esclavos que se encontró vigente cuando ocurre la independencia americana. Los negros trabajaban en la agricultura costeña $o$ en los servicios domésticos. No llegaron a ambientarse en zonas de altura. La manera de hacerlos personas libres, es decir, declararlos manumisos se llevaba a cabo en dos formas: en forma voluntaria de parte del amo, expresa o tácita. $\mathrm{y}$ en forma forzosa por mandato imperativo de la ley. En forma voluntaria y expresa ocurre cuando el amo se presentaba ante el juez o declaraba su voluntad libertaria a favor del esclavo, por escrito. En forma tácita la manumisión operaba cuando el amo lo instituía heredero o cuando el esclavo tomaba las órdenes sagradas. Por ministerio de la ley ocurría cuando el esclavo era desatendido por el señor, hallándose en la vejez o en la orfandad, como premio de una acción gloriosa o por la dejación de ciertos amos. Se manumitia al esclavo, también, por habérsele considerado libre y estar en esta condición, en buena fe por diez anos y sin ella por treinta años. Tiene importancia para el problema de la esclavitud, el hecho del matrimonio. Se prohibieron las uniones entre hombres libres y negros, a diferencia de lo estatuido sobre matrimonio entre indios y blancos, lo que vino del derecho indiano.

\section{Legislación acerca de indios}

Los decretos de Bolivar, dictados en 1824 y 1825 , atentaron contra el derecho indiano al disolver tácitamente la comunidad de indígenas. Las tierras de ella fueron repartidas a los comuneros y serían considerados los aborigenes como propietarios exclusivos y absolutos de estas heredades. Por unas disposiciones se les transformó en propietarios. Una ley de 1828 prescribió que la nación reconocia a los indios mestizos como dueños con pleno dominio de las tierras que en la fecha ocuparan por reparto o sin contradicción a los que no dispusieron de tierras. Al dictarse esta ley se signaron los lotes de tierras correspondientes a ellos y los indios que supieran leer y escribir podian enajenar libremente sus tierras. Antes de Bolivar. San Martin habia promulgado un decreto por el que no deberia hacerse una separación entre los indios y los demás peruanos. Todas las perso- 
nas deberian ser reconocidas por este ủltimo nombre. Se abolió también tcóricamente las mitas, pongos, encomiendas, yanaconazgos y toda clase de servidumbre personal aunque éstas se presentaron en la realidad durante la azarosa vida republicana y fueron regulados por la ley. Ninguna persona podía forzar a los peruanos a que sirvieran a terceros contra su voluntad libre. El Código Civil de Santa Cruz sólo se ocupó de los indios al fijar normas sobre los testamentos que pueden otorgar y no les confirió norma protectora alguna (5). El Código Civil de 1852 no los menciona como tampoco legisla sobre la comunidad de indígenas, la que desapareció del mundo juridico por no tener existencia legal para reaparecer en la Constitución Política de 1920 y en el Código Civil de 1936 (6).

\section{Relaciones entre el Estad o y la Iglesia}

Caracteriza el derecho intermedio peruano la supervigilancia sobre el clero, especialmente el regular. El Estado que surgió de la guerra de la reconquista española fue protector y amparador de la Iglesia. La conquista de América se hizo en nombre de la propagación de la fe y de la doctrina de Cristo. Pero, a su vez, Espana pretendió influir sobre la organización religiosa. Obligó a la reunión del Concilio de Trento; forzó en él ciertas decisiones dogmáticas e intentó, con Carlos V y Felipe II, influir en las elecciones papales. La Iglesia española procedió con cierta independencia del Papa frente a la resistencia de Roma. Para ciertos actos del rey, hubo juntas de teólogos que autorizaban su realización. Estos regalistas. o sea defensores de las regalias o derechos del Estado frente a las intromisiones de la iglesia en la vida civil, se trasladaban a España para excitar el contacto entre el clero español y Roma. Los reyes entorpecieron las apelaciones a la curia de esa ciudad. Establecieron también el Tribunal de la Nunciatura, residente en España, con jueces espanoles pero dependientes del nuncio. y permitieron los recursos de fuerza que eran apelaciones al tnbunal secular cuando los juzgados eclesiásticos querian extralimitarse en los asuntos civiles, de modo que la sentencia quedaba suspendida hasta la nueva decisión. Defendicron el place y exequátor o pase regio. que consistía en el examen previo de las disposiciones del papado, que se publicaran en España. Las audiencias podían retener las bulas consideradas contrarias al patronato real. Protegieron la reunión de concilios provinciales con delegados del rey. La legislación intentó combatir las manos muertas y la amortización de bienes.

(5) Basadre, Jorge. Historia del Derrebo Premawa. Lima, 1984. Se utiliza en esta cita la ufuma
edicion de este libeo,

Basadre, Jorze. Op. cit. 
El Estado dotaba de rentas a las iglesias y presentaba los pretendientes a los oficios eclesiásticos. El clero fue, en general, más servil al rey con América que con Espafia y se llegó a afirmar que la Iglesia de Indias fue movida desde Madrid y no desde Roma. El rey fue considerado Vicaro General del Pontífice en el continente descubierto y colonizado por España, y así un libro del jurista Solórzano, defendiendo una teoría contraria, fue prohibido.

El siglo XVIII, gobernado por la dinastía de los borbones, presentó un regalismo más acusado, bajo el influjo del galicanismo. - A fines de ese siglo, el clero estaba en parte influido por el enciclopedismo. Los borbones llegaron a la ruptura con Roma y al destierro del nuncio. Después de un arreglo y un nuevo aislamiento fueron a los concordatos de 1737 y 1753. El Estado organizó la totalidad de sus pretensiones al patronato con pocas excepciones. Se le obligó a las manos muertas y al pago de impuestos, y ciertas rentas que antes eran eclesiásticas fueron concedidas al Estado. Durante el reinado de Carlos III, se multiplicó el paso regio para las cuestiones de dogma y de fe. Tratándose de documentos papales, se creó el Tribunal de la Rota con jueces especiales propuestos por el rey para asuntos eclesiásticos y se autorizó la inspección de los concilios por el poder civil. A la muerte del Papa Pío VI, en 1799, las relaciones de España con Roma fueron suspendidas hasta que se comunicara la nueva decisión.

Dentro de estos precedentes surgió la revolución de la independencia. El Presidente Santa Cruz reglamentó al clero regular; suprimió los conventos con menos de ocho religiosos, dedicándolos a fines de instrucción; entregó la administración de las rentas de los conventos a ecónomos laicos; facilitó los permisos de desclaustración para lo que declaró expedito el recurso de fuerza. Con fecha 17 de diciembre de 1851 , se promulgó una ley de elección de Obispos por los curas de las diócesis. En la literatura política, como en el regalismo, Vidaurre es un ejemplo de esta postura anticlerical. Un ex-sacerdote, Vigil, escribió el libro "Defensa de la Autoridad de los Gobiernos y de los Obispos contra la pretención de la Curia Romana" y cuando el sumo pontífice lo excomulgó, remitió una famosa "Carta al Papa". Vigil llega a ser gran figura ideológica del Perú republicano del siglo $\mathrm{XIX}$.

El patronato nacional republicano fue heredero del patronato regio concedido por la Santa Sede a la monarquía de Castilla. Al producirse el proceso emancipador, las naciones republicanas reivindicaron este patronato a favor de sus gobiernos. En el caso peruano, el Papa Pio IX lo otorgó formalmente por medio de su bula "Praeclara inter beneficia" y 
en el gobierno de Nicolás de Piérola se incorpora a la legislación peruana, por decreto de 27 de enero de 1880 , en plena guerra con Chile.

Este sistema de patronato nacional que tantas polémicas desató entre regalistas y ultramontanos cesó por mandato del Decreto Ley 23147 dictado durante el gobierno militar del general (retirado) Francisco Morales Bermúdez Cerruti y la iglesia Catolica en el Perú goza ahora de plena independencia y autonomia, con pursonería jurídica de carácter público y con capacidad plena para adquirir y disponer de bienes y recibir ayudas $y$ subvenciones del exterior.

\section{Régimen de la propiedad inmueble}

Otra característica del derecho intermedio es la acentuación de un régimen individualista en la propiedad inmueble. El jusnaturulismo que tanta influencia ejerció sobre la revolución de la independencia consideró que la propiedad era un derecho natural consistente en la facultad de gozar y disponer de los bienes, rentas y frutos del trabajo y de la industria. Regresó esta tesis a la noción romana del dereche de propiedad civil. En la Edad Media, se había operado una desintegración del concepto de propiedad civil y difundido la division del dominio entre sen̂or y vasallo, propietario y poseedor, pero el "nudo", o sea, el desnudo derecho correspondfa al propietario. Esta situación se prolongó en la Edad Media y llegó a América por un proceso de concesión expansiva de principios juridicos.

Coincidia con el fenómeno de grañ importancia consistente en la sustracción de gran parte de la propiedad de la libre circulación, o sea. a la prohibición de cambios en cuanto a su dueno. Esta inmovilización tenia varias causas. La propiedad, muchas veces, estaba amortizada como en el caso de las vinculaciones y estaba acumulada en manos de personas juridicas que no podian disponer de ellas como era el caso de las "manos muertas". El problema jurídico de las vinculaciones y sus implicancias prácticas proviene del Derecho indiano. La vinculación no es una institución especial sino una forma excepcional del régimen jurídico de la propiedad, un estado, una situación civil o fase de la misma. Vincular es privar a la propiedad de su condición de ser libremente enajenada y transmisible por actos inter vivos o mortis causa, sujetándola a un orden predeterminado o irreformable en la sucesión de su disfrute. Vincular es crear un lazo que une indefinidamente a la porción de bienes vinculados en la forma de un todo juridico dentro de una familia o de una persona determinada según la regla de los llamados a la sucesión de los mismos. Hubo tres especies o formas vinculares especiales: una civil, los mayorazgos, y. dos eclesiásticas: los patronatos y las capellanías. Los mayorazgos tuvie- 
ron por objeto perpetuar el nombre de una familia, haciendo que se conserve integra la fortuna en poder de uno de los miembros de ella, y que de éste pase a otro y asi sucesivamente (7). Se les denominó instituciones de orgullo y de vanidad para quien tenia descendientes varones pudiera transmitir su nombre a la posteridad remota, y tener el orgullo de conservar integra su fortuna hasta los siglos venideros.

Los mayorazgos podian ser perpetuos y temporales, regulares o irregulares. Eran mayorazgos perpetuos los que nunca terminaban, a diferencia de los temporales que tenían su expiración después de un número de sucesiones, por voluntad del fundador. El mayorazgo era regular cuando el fundador designaba a su hijo primogénito varón, después al primogénito de éste, y así sucesivamente, con preferencia del mayor sobre el menor, el varón a la hembra. El mayorazgo irregular dependía de la voluntad irrestricta del fundador y el orden variaba de acuerdo a su criterio. Se llegaron a conocer nueve especies de mayorazgos irregulares. Por ejemplo, en el mayorazgo electivo cada poseedor tenia la facultad de elegir al que habia de sucederle, ya fuese uno de sus hijos u otro pariente.

En lo que se refiere al mayorazgo indiano, no hay reglamentación especial. Sobre el mayorazgo solamente existen informes de las audiencias sobre la cuantía de la fortuna personal cuando se queria establecer. Este corresponde a una época cuando la institución de mayorazgo se restringe; pues ocurre en el siglo XVII que solamente pudo establecerse cuando el lustre de una casa familiar así lo permitía. Una ley de 1789 dificultó la formación del mayorazgo. Existe, pues, un derecho consuetudinario, la reglamentación de las Leyes de Toro, de restricción del mayorazgo $y$, por último. de su extinción legal. $Y$, aquí en el Perú ocurrió un fenómeno muy curioso. El Perú proclamó su independencia en nombre de la igualdad, pero España habia abolido los mayorazgos antes que la república nueva. En cambio, hubo recepción del derecho indiano en el Perú republicano, y. San Martín dispuso que la legislación española continuara rigiendo pese "al grito emancipador".

Solamente la Constitución de 1828 estableció que la propiedad era enajenable $y$, de acuerdo con dicha disposición, una ley dictada el 20 de diciembre de 1829, dispuso que los poseedores de un mayorazgo podían enajenar o disponer de ella. Pero, para enajenar la mitad de un mayorazgo se necesitaba llamar al sucesor. Esto originó muchos litigios y que gran

(7) García Cakderón, Francisco, Diccionario de Legislación Perwana. Lima, 1879. Segunda edi. ción, pagina 1322 . 
cantidad de mayorazgos continuaran rigiendo en plena república hasta que se promulgó la ley de 4 de setiembre de 1849 , durante el gobierno de Castilla, que obligaba a la división del mayorazgo. La legislación habia dado así el tiro de gracia al mayorazgo mucho después de proclamada la independencia. La ley de España fue del ano 1841 y el Perú se inspiró en su antigua metrópoli. Ahora bien, el lector no debe confundir los bienes que algunos poseedores de mayorazgos perdieron durante la guerra de la Independencia con la institución en si. Por su actitud favorable a la causa que originó pleitos posteriores, pero estas expoliaciones tuvieron razones políticas o patrióticas al margen de las cuales durante los primeros años de la república se crearon otros mayorazgos.

Merece destacar el concepto de las vinculaciones eclesiásticas, los patronatos y las capellanias que tienen origen castellano. Hay que distinguir entre patronato de Derecho público y patronato de Derecho privado Este último consistía en el derecho de presentar un clérigo para servir en una iglesia o beneficio vacante gozando además de ciertos derechos. Era una vinculación eclesiástica. Provenía del hecho de haber construido. dotado o fundado una iglesia o beneficio comprendidos dentro del patronato o por heredar ese derecho. La capellanía era la obligación de celebrar cierto número de misas según lo estuviere proveído por el fundador o de desempenar ciertos cargos. Habia capellanias legas o mercenarios, sin intervención de la autoridad eclesiástica o con autorización de ésta.

Otra forma especial que el régimen de la propiedad indiana contenia era, como se ha anotado, el de las manos muertas. Estas eran instituciones que no podian vender bienes pero si podian adquirirlos. Generalmente. eran personas religiosas como conventos y monasterios. La abundancia de manos muertas explica que para la propicdad colonial tenia la importancia que hoy reviste el contrato de compra-venta. Otro contrato que no implica la traslación de dominio sino un régimen más complicado fue el censo. Por antonomasia se consideraba que el contrato de censo era el de enfiteusis. Por la enfiteusis, una persona transmitia a otra el dominio útil de un fundo por cierto rédito o por un canon anual conservando el dominio directo. He aqui el caso típico de la desmembraciôn del dominio que la Edad Media habian elaborado. De un lado, el goce $y$, de otro lado, el nudo derecho. El censatario, o sea, el que recibe el dominio útil, podía disponer de la finca y hasta enajenarla. El señor concedente, por su parte. conservaba algunos derechos. Pero también se dio el nombre de censos a otros contratos. El propietario de un inmueble podía cederlo a cambio de una pensión anual: era el censo reservativo. El dominio no se dividia como en el caso de la enfiteusis. Se transmitía con la limitación consistente en el pago de un canon anual, único derecho que se reservaba al ceden- 
te. También podía ocurrir que el duefio de un capital lo imponia sobre un inmueble ajeno recibiendo a cambio una pensión. La pensión era una especie de interés del capital impuesto. El inmueble gravado resultaba algo así como una garantía para el inversionista. La pensión en canon era deducida de los frutos. Era un medio por el cual personas y entidades que tenian capital sobrante y disponible podían colocarlo sin peligro. Se llamaba este contrato censo reservativo.

Existían otras formas variadas de contrato sobre la propiedad que no alcanzaban la nitidez y sencillez del contrato de compra-venta. Uno, sobre todo, tiene interés para la historia del Derecho peruano que proviene del indiano: el derecho de llave. En la ciudad de Lima, precisamente en los alrededores de la plaza mayor de la capital, hubo el caso de tiendas de comercio sujetas a un pacto llamado "derecho de llave". ¿Qué fue este derecho de llave? Al amparo de la libertad contractual que entonces existió dentro de la figura del arrendamiento, porque sólo el código de Napoleón Bonaparte limitó la duración del arrendamiento, en el curso de la época colonial se fijó un determinado pacto anexo al arrendamiento, llamado derecho de llave o juanillo. Se producía de acuerdo con él, un verdadero desmembramiento del dominio sobre un inmueble. Se concedia un verdadero derecho de usar y usufructuar la cosa inmueble, con la facultad de traspasarlo a una tercera persona. El primitivo propietario de la cosa sólo conservaba el derecho de percibir indefinidamente la renta del bien. Fueron muy numerosos durante la época de Derecho indiano estos contratos, muy antiguos, y, por esa razón, en muchos casos el documento original se perdió. Faltaba, pues, el instrumento inicial que originó la relación jurídica derivada de este derecho de llave. El Código Civil de 1852 no lo legisló. como no legisló sobre el yanaconaje y silenció el régimen de comunidades indigenas. Pasó el tiempo y por la evolución de la ley, surgió la tendencia a movilizar la propiedad, y entonces se encontraron los jueces y tribunales con la necesidad de redimir el derecho de llave. No hubo, sin embargo, en muchos casos, contrato escrito y en ningún caso había ley que regulara esta situación.

En los "Anales Judiciales del Perú", se nota cómo la jurisprudencia peruana ha tratado el derecho de llave. Existen, al respecto, variadas ejecutorias supremas de los años de $1887,1905,1911,1913$ y 1916. Toda esta jurisprudencia frondosa es contradictoria y viene de un fárrago de problemas derivados del Derecho indiano. Se discute en ella el derecho de llave, su alcance juridico y los modos de la redención del mismo. El doctor Guillermo A. Scoane, quien fuera distinguido fiscal de la Corte Suprema de la República y gran jurista peruano, en un dictamen enjundioso identifica este derecho de llave con la enfiteusis. El doctor Ezequiel F. 
Munoz lo identificó con el contrato de arrendamiento y en una ejecutoria suprema de 1916, Manuel Vicente Villarán opina que el derecho de llave tiene un carácter análogo al antiguo censo reservativo. Para comprender este tema, deben mencionarse los caracteres principales del derecho de propiedad en la época del derecho indiano. En esta etapa predominó la gran propiedad, o sea la concentrada en pocas manos o personas. Hubo además, la circunstancia de que muchas personas individuales o colectivas, propietarias, no podían enajenar los bienes. Debido a esta situación se produjo un fenómeno que tipifica la propiedad en la colonia: una separación entre el goce a largo plazo, que se concede al que trabaja, y el derecho nudo que queda en manos del verdadero propietario. Fue una situación de tal importancia que cuando se produjo en la época del Conde de Superunda, Virrey del Perú, un terremoto que dejó en cimientos a la ciudad de Lima, se pensó entonces trasladar la ciudad a un lugar que ofreciera menor peligro frente a los sismos. $\mathrm{Y}$ se produjo un conflicto entre los que tenían un título de propiedad y otros que tenían el simple goce Los primeros se opusicron al traslado de la capital por el perjuicio que éste les podía irrogar, $\mathrm{y}$, los segundos fueron partidarios de la medida El pleito no alcanzó a ser resuelto por el virrey, y fue enviada la cuestión a la corte de Madrid. La capital sigue en Lima pese a los terremotos que la han remecido $\mathrm{y}$ a las predicciones sobre la inminencia de nuevos movimientos telúricos.

\section{El Código Civil de 1852 y el olvido del derecho indiano}

Los autores del Codigo Civil de 1852 se inspiraron en el método de las Institutas y no en el del Código francés porque éste no tenia un libro especial dedicado a los contratos y obligaciones. El derecho castellano pudo haberse irradiado sobre este texto civil codificado republicano bajo una doble influencia: como derecho peninsular y como derecho indiano. La nueva república debió ir a un proceso de recepcionar las normas protectoras para los aborigenes y sus costumbres y hacerlas cumplir y lo más curioso es que los radicales que pretendieron ir a introducir reformas en el matrimonio y combatir los privilegios de la lglesia se olvidaron de evitar la opresión de los indios. La idea de república lleva imbibita de proteger al indio. La comunidad agraria, que era una forma posesoria tradicional para el cultivo de la tierra, fue ignorada y silenciada en el Código Civil de 1852. El codificador peruano prefiere abrazar los postulados en boga de la filosofia teorica y racionalista y coloca al aborigen como un ente abstracto en igualdad que con cualquier peruano. El derecho indiano no llega a influir en este Código Civil con la fuerza que debio hacerlo, aunque algunas de sus huellas se dejan sentir. 
En lo que atañe a la influencia española, debemos remarcar que el Código Civil peruano de 1852 fue un texto que recoge la esclavitud y algunas disposiciones del derecho familiar tienen origen colonial. Por eso, el Código peruano se separa del francés al adoptar el matrimonio tridentino y la tesis antidivorcista que conlleva una realidad colonial que es parte de ese pasado del que no se podia romper pese a los años desde la independencia al Código Civil.

El Código Civil peruano de 1852 reguló los censos enfitéutico, consignativo y reservativo y, a tal efecto, sigue el influjo castellano. El articulo 1907 de este Código expresó que el censo enfitéutico nunca revive cuando ha sido extinguido por algunos de los modos señalados por la ley y el parágrafo 1909, del mismo texto, prohibió gravar los bienes inmuebles con censos o vinculaciones perpetuas repitiendo los postulados de la Novísima Recopilación (8).

En cuanto al régimen sucesorio, la mejora aparece con notas típicas provenientes del derecho castellano. Se mantiene la legítima de un quinto y la de un tercio proveniente del derecho indiano y también la constitución de las reservas, tanto ordinaria como extraordinaria (Título 60., Sección 5a., libro 2o.), la desheredación (Título 16, sección 4, libro 2o.) y la colación de bienes (Título 20 de la misma sección y libro). Por ello, el código peruano viene a tener una nota más conservadora que el posterior código civil español.

Finalmente, al hacer breves consideraciones sobre el código civil peruano de 1852, debe resaltarse que la costumbre no fue considerada como fuente jurídica aunque puede encontrarse existente en algunas de las normas sobre clérigos, matrimonio tridentino, recusación del divorcio, herencia, reservas, capellanías, patronato y esclavitud, entre otros temas que trata. En el fondo, el codificador peruano del año cincuentidós respetó la costumbre, pero no aparece ella como un elemento esencial ya que ésta venía de un pasado que la nueva república pretendía olvidar, sin vislumbrar las desgracias nacionales que ocurririan treintisiete años después. No llega a ser preponderante la influencia del derecho indiano para un legislador que estuvo fascinado por el nuevo proceso codificador europeo francés. La irradiación del derecho indiano se sustituye por la influencia jurídica que ejercita España a partir del año 1852. 